\title{
Erratum
}

Curr Genet (1994) 26:198-207

\section{Centromere promoter factors (CPF1) of the yeasts Saccharomyces cerevisiae and Kluyveromyces lactis are functionally exchangeable, despite low overall homology}

Wietse Mulder $^{1}$, Aaron A. Winkler ${ }^{2}$, Inge H.J.M. Scholten ${ }^{1}$, Ben J. M. Zonneveld ${ }^{2}$, Johannes H. de Winde ${ }^{1}$, H. Yde Steensma ${ }^{2}$, Leslie A. Grivell ${ }^{1}$

${ }^{1}$ Section for Molecular Biology, Institute for Molecular Cell Biology, Biocentrum Amsterdam, Kruislaan 318 ,

NL-1098 SM Amsterdam, The Netherlands

${ }^{2}$ Department of Molecular and Cellular Biology, Leiden University, Wassenaarseweg 64, NL-2333 AL Leiden, The Netherlands

Due to an unfortunate error, an incomplete version of Fig. 3 was published in the above article. The correct version is printed below.

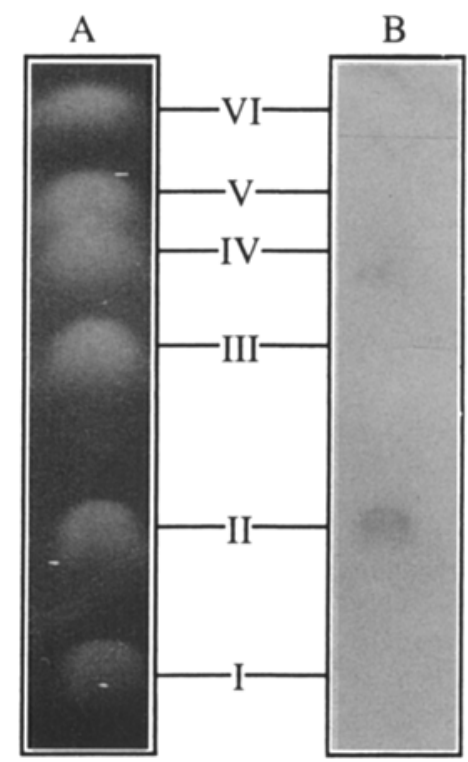

